\section{Death from Paraquat after Subcutaneous Injection}

Brit. med. F., 1967, 3, 721

Gramoxone is a commercial formulation of a herbicide containing the di-metho sulphate salt of paraquat $\left(1,1^{\prime}\right.$-dimethyl-4, 4'-dipyridilium).

Bullivant (1966) reported that up to July 1964 one case of paraquat poisoning had occurred in a child in Ireland. $\mathrm{He}$ described two additional cases in men in 1966. The first was that of a 28-year-old man who drank half a glass of $20 \%$ paraquat solution; a day later gastrointestinal symptoms appeared, followed by signs of hepatorenal damage. He died of severe respiratory failure. The second case was that of a man aged 23 who drank a mouthful of paraquat and vomited immediately. In this case also signs of mild hepatorenal damage appeared, and he too died of respiratory failure.

The purpose of this paper is to present an additional case of paraquat poisoning, this time by subcutaneous injection. Suicide in such an unusual way has not to our knowledge been described in medical literature.

\section{CASE Report}

The patient was a 30-year-old Yemeni-born farmer, divorced, who emigrated to Israel 21 years ago. He was known from the records of a mental hospital to suffer from paranoid schizophrenia.

On 2 August 1966, by means of a syringe that was used for immunizing chickens, he injected himself with approximately $1 \mathrm{ml}$. of a $20 \%$ solution of Gramoxone. He was admitted to hospital a few hours later after vomiting and passing loose bloody stools. He was found to be in good general condition. His pupils were equal and reacted to light. His pulse was 76 and blood pressure 130/80. No other abnormal physical findings were observed. Two days after admission a right facial paresis occurred, abdominal reflexes were reduced on the right side, and Oppenheim's sign was present on the left side. On the fifth day after admission these findings were no longer elicited. Laboratory findings were not abnormal except that urinary sediment contained some erythrocytes and leucocytes. Blood urea varied from 69 to $140 \mathrm{mg} . / 100 \mathrm{ml}$. and urinary output from 1,000 to 2,000 ml. a day. An E.C.G. was within normal limits.

For two days after admission he felt well, but on the third day he complained of anorexia and chest pain, and his temperature rose to $39^{\circ} \mathrm{C}$. He had no dyspnoea at this time. $X$-ray examination during this phase showed a slight infiltrative shadow of the right lung base. After five days he again improved, his pain disappeared, and his temperature returned to normal. In spite of this his radiological changes persisted. On the eighth day in hospital jaundice appeared.

He was tender in the right hypochondrium and the liver was felt $6 \mathrm{~cm}$. below the costal margin. Total serum bilirubin values were raised to $4.6 \mathrm{mg} . / 100 \mathrm{ml}$., of which direct bilirubin was $3 \mathrm{mg}$./ $100 \mathrm{ml}$., and the serum S.G.O.T. rose to 250 units. Serum ammonia was $375 \mu \mathrm{g} . / 100 \mathrm{ml}$. and leucine aminopeptidase was 364 units. All these findings disappeared by the 11th day. The patient felt well for the next three days, but on the 14th day he developed dyspnoea and tachycardia, both of which increased in severity. $X$-ray examination of the chest showed bilateral areas of opacity and deviation of the mediastinum to the left. The patient became oxygen-dependent, and his condition worsened steadily until he died in severe respiratory distress on the 18th day.

Necropsy Findings. - The kidneys did not show any macroscopic or microscopical pathological changes; the liver did not show macroscopic changes, but histological examination revealed some swollen periportal hepatic cells. The main findings were found in the lungs ; the upper lung segments were swollen and emphysematous, and there was evidence of intrapulmonary haemorrhages as well as subpleural petechial haemorrhages, the lower segments were contracted and showed bilateral atelectasis.
Microscopical Findings.-The most striking change was proliferation of epithelium of the terminal bronchioles. In many places this proliferation partly or completely occluded the lumen at the prealveolar ducts. The epithelial cells were themselves cuboidal with nuclei rich in chromatin (Reif and Herzig, 1967).

\section{Discussion}

There are some findings common to our case and the two cases published by Bullivant (1966). All began with gastrointestinal disturbances, though in our case poisoning followed a subcutaneous injection, and evidence of hepatorenal damage followed the gastrointestinal disorders. Death was due to progressive pulmonary failure. Transient general neurological signs which were seen in our case were not mentioned in the two other cases, but in laboratory animals Clark et al. (1966) showed that initial neurological symptoms did occur. If the animal did not die during this phase the deaths were due to respiratory failure. Histologically, an identical pulmonary proliferative process was found, especially in rats and mice, and less in rabbits.

Daniel and Gage (1966), working with laboratory animals, showed that $96 \%$ of paraquat labelled with ${ }^{14} \mathrm{C}$ was excreted unchanged in the urine within three days of its subcutaneous administration.

We could not find paraquat in the patient's urine and sputum three days after admission. It seems, therefore, that this substance initiates proliferative changes, which continue though it itself is no longer present.

Such a proliferative process is not unique and has been said to follow the administration of carcinogenic compounds to laboratory animals (Ackerman and Regato, 1954). It is interesting to note that, after subcutaneous injection of carcinogenic hydrocarbons in high-pulmonary-tumour strains of mice, diffuse proliferative changes could, as early as two weeks, be detected, partly projecting into the lumen of alveoli. In the fifth week pulmonary tumours were diagnosed in some strains (Ackerman and Regato, 1954). We felt that this similarity should not be overlooked, and we suggest that further work should be done with paraquat to clarify its mode of action and to show whether or not it, too, is a carcinogen.

The estimated fatal dose would be $4 \mathrm{mg}$. $/ \mathrm{kg}$., which would explain why only a mouthful of it could also be fatal despite the poor absorption of this type of compound.

It may be mentioned that the liver and kidneys did not show anything gross pathologically in spite of the presence of clinical hepatorenal infection.

We are grateful for the help given by Dr. A. Reif, head of the Department of Pathology at Asaf Harofe Government Hospital, and Dr. E. Herzig, assistant in that department. We wish to express our thanks to Dr. E. Vure, head of Paediatric Department "B" at the above hospital, for his helpful advice.

$$
\begin{aligned}
& \text { Ch. AlmoG, M.D., } \\
& \text { Head of Department. } \\
& \text { E. TAL, M.D., } \\
& \text { Assistant. }
\end{aligned}
$$

Medical Department “ C,"

Asaf Harofe Government Hospital. Zrifin, Israel.

\section{REFERENCES}

Ackerman, L. V., and Regato, J. A. del (1954). Cancer; Diagnosis, Treatment, and Prognosis, 2 nd ed., pp. 40, 45. St. Louis.

Bullivant, C. M. (1966). Brit. med. F., 1, 1272.

Clark, D. G., McElligott, T. F., and Hurst, E. W. (1966). Brit. F. industr., Med., 23, 126.

Daniel, J. W., and Gage, J. C. (1966). Ibid., 23, 133.

Reif, A., and Herzig, E. (1967). To be published. 